\title{
Sound sequence discrimination learning motivated by reward requires dopaminergic D2 receptor activation in the rat auditory cortex
}

\author{
Masaharu Kudoh ${ }^{1}$ and Katsuei Shibuki \\ Department of Neurophysiology, Brain Research Institute, Niigata University, 1-757 Asahimachi-dori, Niigata 951-8585, Japan
}

\begin{abstract}
We have previously reported that sound sequence discrimination learning requires cholinergic inputs to the auditory cortex $(A C)$ in rats. In that study, reward was used for motivating discrimination behavior in rats. Therefore, dopaminergic inputs mediating reward signals may have an important role in the learning. We tested the possibility in the present study. Rats were trained to discriminate sequences of two sound components, and licking behavior in response to one of the two sequences was rewarded with water. To identify the dopaminergic inputs responsible for the learning, dopaminergic afferents to the AC were lesioned with local injection of 6-hydroxydopamine (6-OHDA). The injection attenuated sound sequence discrimination learning, while it had no effect on discrimination between the sound components of the sequence stimuli. Local injection of 6-OHDA into the nucleus accumbens attenuated sound discrimination learning. However, not only discrimination learning of sound sequence but also that of the sound components were impaired. SCH23390 (0.2 $\mathrm{mg} / \mathrm{kg}$, i.p.), a D1 receptor antagonist, had no effect on sound sequence discrimination learning, while it attenuated the licking behavior to unfamiliar stimuli. Haloperidol $(0.5$ $\mathrm{mg} / \mathrm{kg}$, i.p.), a D2 family antagonist, attenuated sound sequence discrimination learning, while it had no clear suppressive effect on discrimination of two different sound components and licking. These results suggest that D2 family receptors activated by dopaminergic inputs to the $A C$ are required for sound sequence discrimination learning.
\end{abstract}

Sound sequence is critical information required for recognizing complex stimuli such as speech sounds. The importance of the auditory cortex (AC) in sound sequence discrimination has been suggested by various studies. AC neurons respond selectively to a particular sequence of sounds (Suga et al. 1978; Kilgard and Merzenich 2002; Nakahara et al. 2004). The auditory response of AC neurons can be either enhanced or inhibited by preceding sounds (McKenna et al. 1989; Brosch et al. 1999; Brosch and Schreiner 2000). The discrimination of temporal auditory patterns is impaired by ablation of the AC (Diamond and Neff 1957; Kaas et al. 1967; Dewson and Cowey 1969). We have demonstrated that sequence discrimination learning in rats is facilitated by cholinergic inputs to the AC (Kudoh et al. 2004).

Behavioral learning is motivated by a reward. Reward signals are thought to be mediated by dopaminergic neurons originating in the ventral tegmental area in the midbrain and terminating in the limbic system and neocortex (Schultz 2001). In animals performing sound discrimination learning, dopaminergic metabolites are detected in the neocortex, including the medial prefrontal cortex (mPFC) and AC (Stark and Scheich 1997; Stark et al. 2000). Dopamine facilitates the induction of long-term potentiation (LTP) and long-term depression (LTD) in the neocortex (Law-Tho et al. 1995; Otani et al. 1998; Blond et al. 2002). Neuronal plasticity in the AC is induced by sound stimulus paired with electrical stimulation in the ventral tegmental area (Bao et al. 2001, 2003). In our previous behavioral study, water-deprived rats were trained to discriminate between sound sequences using a reward of water (Kudoh et al. 2004). The mechanism of sound sequence discrimination learning has been attributed to neuronal plasticity in the AC (Seki et al. 2001;

\footnotetext{
1 Corresponding author.
}

E-mail kudoh@bri.niigata-u.ac.jp; fax 81-25-227-0814.

Article is online at http://www.learnmem.org/cgi/doi/10.1101//m.390506.
Kudoh et al. 2004). Therefore, it is very likely that the dopaminergic fibers projecting into various brain areas including the AC play an important role in sound sequence discrimination learning.

Main targets of the mesocortical and mesolimbic dopaminergic inputs include the mPFC and the nucleus accumbens (NAc), which are thought to associate between sensory stimuli and rewards or predicted rewards (Schultz 2001). Therefore, the mesolimbic and mesocortical fibers projecting into these structures might play an important role in sound sequence discrimination learning. Dopaminergic fibers can be specifically denervated by local injection with 6-hydroxydopamine (6-OHDA) (Kelly and Iversen 1976). In the present study, therefore, we investigated sound sequence discrimination learning, and tested the effects of local 6-OHDA injection into these brain areas, which may be the responsible target sites for dopaminergic fibers.

To clarify the role of dopaminergic inputs in sound sequence discrimination learning, functions of dopamine receptors were investigated pharmacologically. Dopamine receptors have five subtypes and are divided into D1 (D1 and D5) and D2 (D2, D3, and D4) families based on coupling to adenylate cyclase: D1 facilitates cAMP production, while D2 suppresses it (Kebabian and Calne 1979; Civelli et al. 1993; Lachowicz and Sibley 1997). Thus, D1 and D2 family receptors would have differential effects on neuronal plasticity. It is reported that $\mathrm{D} 1$ but not $\mathrm{D} 2$ receptors are required for LTP induction (Gurden et al. 2000; Kerr and Wickens 2001). Furthermore, differential functions of D1 and D2 receptors have been also reported: D1 is involved in feeding and drinking, while D2 is important in information processing (Clifton et al. 1991; Courtiere et al. 2003; Yue et al. 2004). Therefore, effects of subtype-specific dopamine receptor antagonists on sound sequence discrimination learning were separately investigated. 


\section{Results}

Attenuation of sound sequence discrimination learning by electrolytic lesions in the $\mathrm{AC}$

We have reported that sound sequence discrimination learning can be investigated behaviorally in rats (Kudoh et al. 2004). Discrimination between sequences of two sounds was tested as shown in Figure $1 \mathrm{~A}, \mathrm{~B}, \mathrm{C}$. The percentage of trials in which rats licked the spout during sound presentation was calculated separately for rewarded $\left(\mathrm{S}^{+}\right)$and unrewarded $\left(\mathrm{S}^{-}\right)$sequences (Fig. 1D). Vigorous licking was observed in the first $6 \mathrm{~h}$ of the test sessions. Therefore, we investigated the trials only in this period. In the first session, the rats similarly responded to both $\mathrm{S}^{+}$and $\mathrm{S}^{-}$(Fig. 1D). However, a significant difference between $\mathrm{S}^{+}$and $\mathrm{S}^{-}$was observed in the second $\left(P<0.05\right.$ in all rats, $\chi^{2}$-test $)$, third $(P<0.05)$, and last sessions $(P<0.001)$ (Fig. 1D). Test perfor-
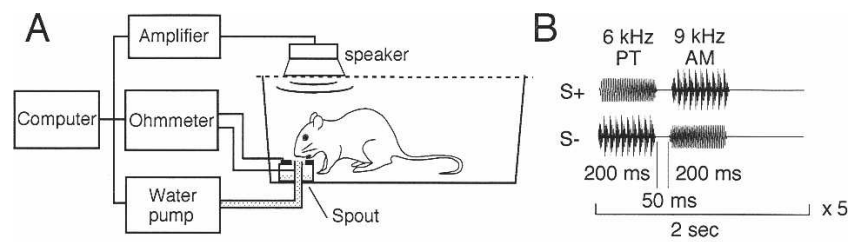

C
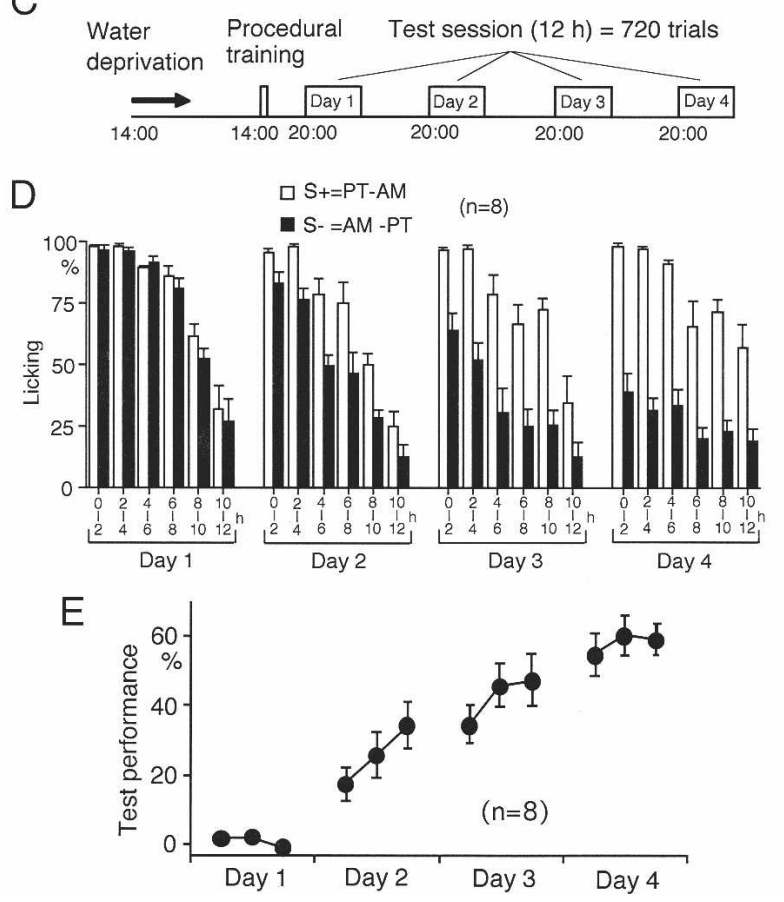

Figure 1. Sound sequence discrimination test. (A) Experimental setup for sound sequence discrimination test. Rats were trained to discriminate between sound sequences in a Skinner box. Licking a spout during sound presentation of a particular sequence was rewarded with water containing $0.1 \%$ saccharine. $(B)$ An example of rewarded $\left(S^{+}\right)$and unrewarded $\left(\mathrm{S}^{-}\right)$sound sequence. A PT and an AM tone with a sawtooth wave were sequentially presented five times at 2-sec intervals. In each trial, either $\mathrm{S}^{+}$ or $\mathrm{S}^{-}$was randomly presented. (C) Schedule of discrimination test. After procedural training for rats to respond to the sound stimuli with licking, 720 trials were repeated at 1 -min intervals during a test session of $12 \mathrm{~h}$. The test session was conducted on four consecutive days. $(D)$ Percentage of trials with licking to sound sequence presentation was calculated separately for $\mathrm{S}^{+}$and $\mathrm{S}^{-}$every $2 \mathrm{~h}$ during the session (mean $\pm S E M$ ). (E) Test performance was estimated as the difference in the percentage of trials with licking between $\mathrm{S}^{+}$and $\mathrm{S}^{-}$. The results for the first $6 \mathrm{~h}$ of the session (mean \pm SEM) are shown.
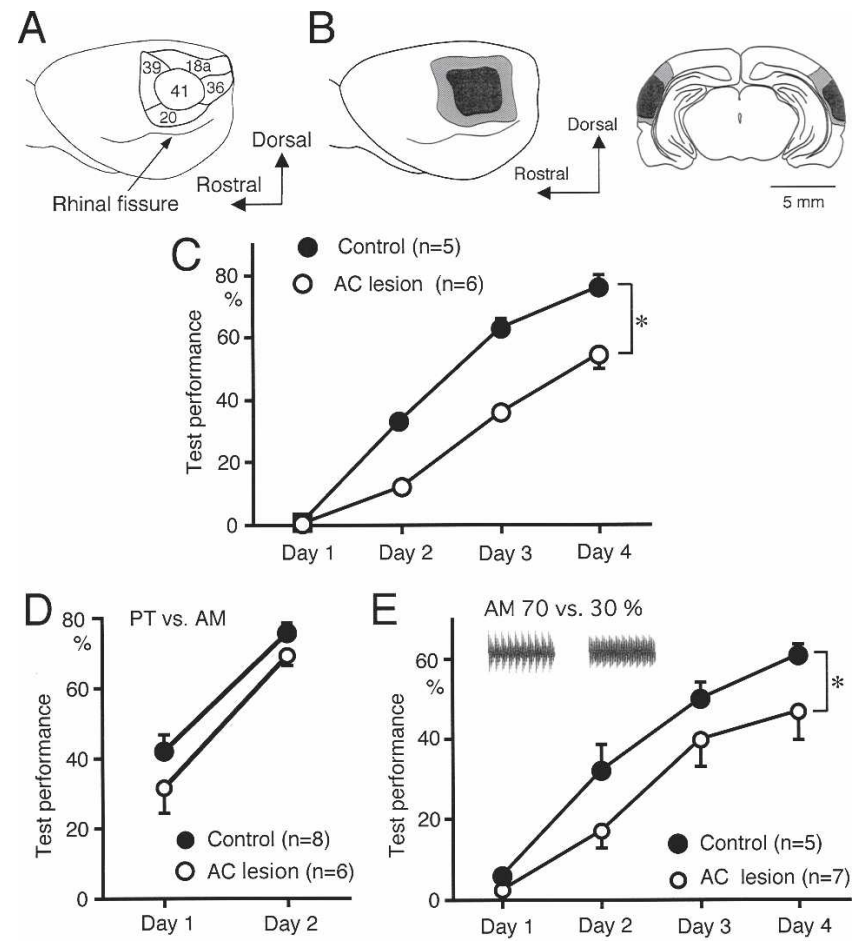

Figure 2. Effects of electrolytic lesions in the $A C$ on sound sequence discrimination learning. (A) Schematic drawing of the AC. Numbers in the figure represent Krieg's brain areas (Krieg 1946). (B) The lesions produced bilaterally in the AC 1 wk prior to the test sessions were histologically confirmed after the behavioral test. The lateral view (left) and frontal section (right) of the brain. Hatched and filled areas represent maximal and minimal extent of the lesions, respectively. (C) The AC lesions attenuated the test performance of sound sequence discrimination compared with that in sham-operated rats $\left({ }^{*} P<0.05\right.$, repeated measures ANOVA). The test performance in the first $6 \mathrm{~h}$ of each session is plotted. $(D)$ The AC lesions had no significant effect on discrimination between the PT and AM sound sequence components. $(E)$ The lesions attenuated discrimination learning between AMs with modulation depths of $70 \%$ and $30 \%\left({ }^{*} P<0.05\right)$.

mance estimated as the difference in the percentage of trials with licking between $\mathrm{S}^{+}$and $\mathrm{S}^{-}$was gradually increased between day 1 and day 4 (Fig. 1E).

To investigate dependence of sound sequence discrimination learning on the $\mathrm{AC}$, a discrimination test was conducted in rats with bilateral electrolytic lesions of the AC. The AC of rats consists of the primary AC (area 41) (Fig. 2A) and surrounding auditory association cortices (areas 18a, 20, 36, and 39) (Fig. 2A) in the temporal cortex (Krieg 1946; Zilles and Wree 1985). Histological examination after the behavioral experiments confirmed the lesions over the primary $\mathrm{AC}$ and surrounding association cortices (Fig. 2B). The test performance of sound sequence discrimination was significantly attenuated in the rats with AC lesions in comparison with that in sham-operated rats $(P<0.05$, repeated measures analysis of variance, ANOVA) (Fig. 2C). The AC lesions had no clear effect on the percentage of trials with licking behavior during the test sessions (data not shown), suggesting that the lesions did not affect motivation of rats. Discrimination between the pure tone (PT) and amplitudemodulated tone (AM), components of the sound sequences, increased markedly between day 1 and day 2 in control rats (Fig. 2D). The AC lesions had no significant effect on this learning (Fig. 2D). These findings demonstrate that the AC is required for sound sequence discrimination learning in rats. 
AC neurons respond well to AMs (Saitoh et al. 1981; Schreiner and Urbas 1988; Gaese and Ostwald 1995), and discrimination learning of AM modulation depths is facilitated by neuronal plasticity in the AC (Sakai et al. 1999). To test whether the effect of the lesions in the AC is specific to sound sequence discrimination learning, discrimination between AMs with modulation depths of $70 \%$ and $30 \%$ were examined (Fig. 2E). The depths of $70 \%$ and $30 \%$ were chosen because the test performance at these depths showed a similar learning curve to that of the sound sequence discrimination (Kudoh et al. 2004). The AC lesions attenuated discrimination learning between AMs of $70 \%$ and 30\% modulation depths $(P<0.05$, repeated measures ANOVA) (Fig. 2E), suggesting that the AC is also required for discrimination learning of AMs.

\section{Attenuation of sound sequence discrimination learning by 6-OHDA lesions in the AC}

To investigate the possible role of dopaminergic inputs to the AC in sound sequence discrimination learning, 6-OHDA ( $8 \mu \mathrm{g})$ was injected bilaterally into the AC $1 \mathrm{wk}$ prior to the test. To check the effect of 6-OHDA, the level of tyrosine hyroxylase was evaluated immunohistochemically after the behavioral experiments. A reduction in tyrosine hydroxylase level was observed in the area extending $2.2 \pm 0.2 \mathrm{~mm}$ (mean \pm SEM, $n=4$ ) in the anteroposterior, $2.4 \pm 0.2 \mathrm{~mm}$ in the dorsoventral, and $1.2 \pm 0.1$
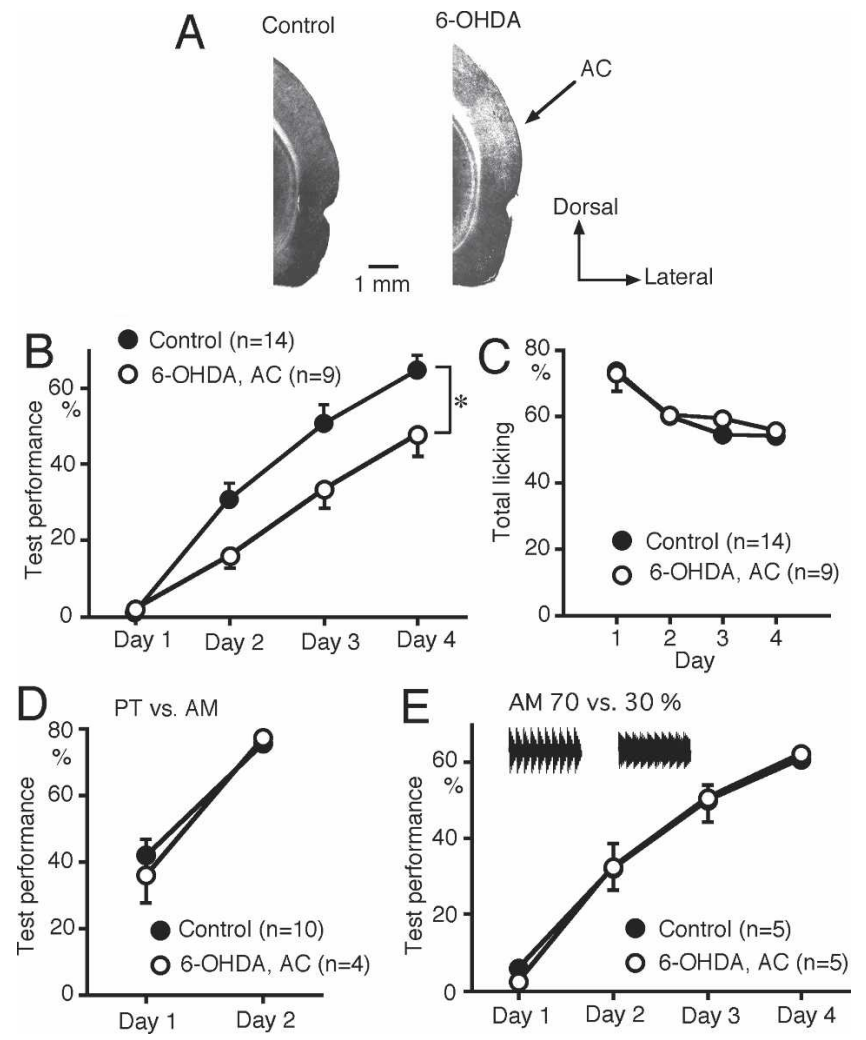

AM 70 vs. $30 \%$

Figure 3. Effects of 6-OHDA lesions in the AC on sound sequence discrimination learning. $(A)$ Immunohistochemical staining of tyrosine hyroxylase in the $\mathrm{AC}$ of a control rat (left) and a rat injected with 6-OHDA into the AC (right). (B) Bilateral 6-OHDA lesions in the AC attenuated sound sequence discrimination $\left({ }^{*} P<0.05\right.$, repeated measures ANOVA with post hoc Scheffe's test). (C) Total number of trials with licking during the test sessions was not attenuated by the 6-OHDA lesions. (D) 6-OHDA lesions had no significant effect on discrimination between the PT and AM. (E) 6-OHDA lesions had no effect on discrimination learning between AMs with modulation depths of $70 \%$ and $30 \%$. $\mathrm{mm}$ in the mediolateral direction in the $\mathrm{AC}$ of rats injected with 6-OHDA (Fig. 3A). 6-OHDA lesions in the AC attenuated sound sequence discrimination learning compared with control (eight naive and six vehicle-injected) rats $(P<0.05$, repeated measures ANOVA with post hoc Scheffe's test) (Fig. 3B). The dopaminergic inputs may be involved in motivation or goal-oriented behavior. However, the total number of trials with licking during the test sessions was not suppressed by the 6-OHDA lesions in the AC (Fig. 3C). The 6-OHDA lesions had no significant effect on discrimination between the PT and AM components of the sound sequences (Fig. 3D). The 6-OHDA lesions in the AC had no effect on the test performance of discrimination between the AMs with modulation depths of $70 \%$ and 30\% (Fig. 3E). These findings indicate that dopaminergic inputs to the AC are specifically involved in sound sequence discrimination learning.

\section{Nonspecific attenuation of sound discrimination learning by 6-OHDA lesions in the NAc}

The NAc is one of the major targets of the mesolimbic dopamine neurons. Bilateral 6-OHDA lesions in the NAc attenuated sound sequence discrimination learning compared with control (eight naive and five sham-operated) rats $(P<0.05)$ (Fig. 4A). The 6-OHDA lesions in the NAc had no effect on either licking behavior in response to sound stimuli during the procedural training (data not shown) or the total number of trials with licking during the test sessions (Fig. 4B). However, the 6-OHDA lesions attenuated discrimination between the components of the sound sequences $(P<0.05)$ (Fig. $4 \mathrm{C})$ and between $70 \%$ and $30 \%$ AMs $(P<0.05)$ (Fig. 4D). These results suggest that the dopaminergic inputs to the NAc facilitate discrimination learning in general. Bilateral 6-OHDA lesions in the $\mathrm{MPFC}$, which is another major target of the mesocortical dopaminergic inputs, had no effect on sound sequence discrimination learning or on licking behavior (Fig. 4F,G). Reduction in tyrosine hydroxylase level was observed in the area extending $3.6 \pm 0.2 \mathrm{~mm}(n=4)$ in the anteroposterior, $3.8 \pm 0.2 \mathrm{~mm}$ in the dorsoventral, and $1.2 \pm 0.1 \mathrm{~mm}$ in the mediolateral direction (Fig. 4E), indicating partial lesions in the mPFC.

\section{Effects of 6-OHDA plus 192lgG-saporine application to} the $A C$ on sound sequence discrimination learning In our previous study, 192IgG-sapporin, a cholinergic immunotoxin, applied to the AC attenuated sound sequence discrimination learning (Kudoh et al. 2004). To explore the functional relationship between the cholinergic and dopaminergic inputs to the $\mathrm{AC}$ in sound sequence discrimination learning, the effects of 192IgG-saporin and 6-OHDA application to the AC were compared. Sound sequence discrimination learning was attenuated to a similar degree by 6-OHDA or 192IgG-saporin application to the AC $(P<0.05$, repeated measures ANOVA with post hoc Scheffe's test) (Fig. 5). Concurrent application of 6-OHDA and 192IgG-saporin to the AC produced no further attenuation in sound sequence discrimination learning compared with the effects produced by 6-OHDA or 192IgG-saporin alone (Fig. 5). The attenuation produced by 6-OHDA or 192IgG-saporin alone, or 6-OHDA plus 192IgG-saporin, was similar to that observed after bilateral AC lesions (Fig. 2), suggesting that both cholinergic and dopaminergic inputs to the $\mathrm{AC}$ are required for the normal function of the AC in sound sequence discrimination learning.

\section{Suppression of licking behavior by D1 receptor antagonists}

We investigated the role of dopaminergic inputs by pharmacological experiments. Chlorpromazine ( $2-5 \mathrm{mg} / \mathrm{kg}$, i.p.), a nonselective dopamine antagonist, was systemically administered 30

\section{Learning \& Memory}



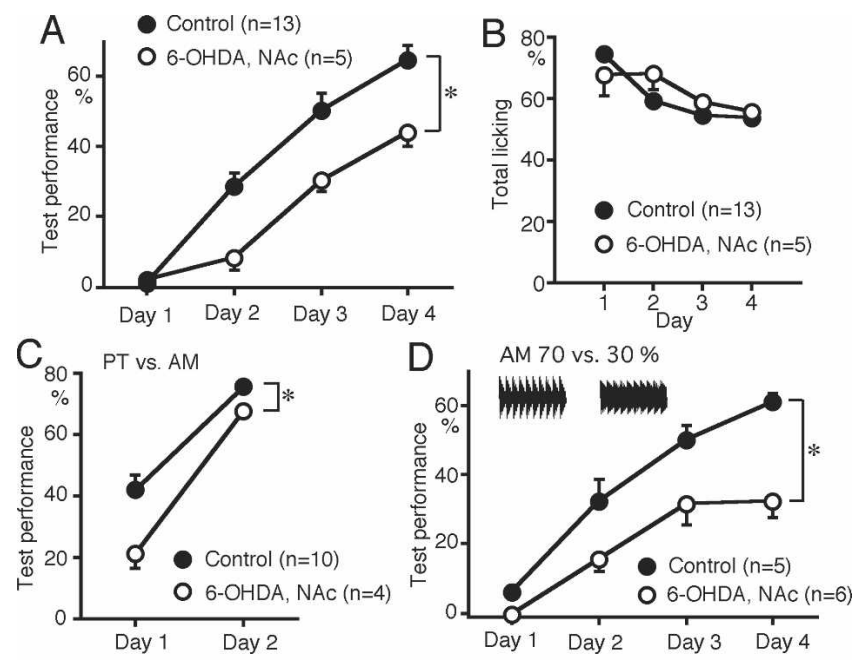

AM 70 vs. $30 \%$
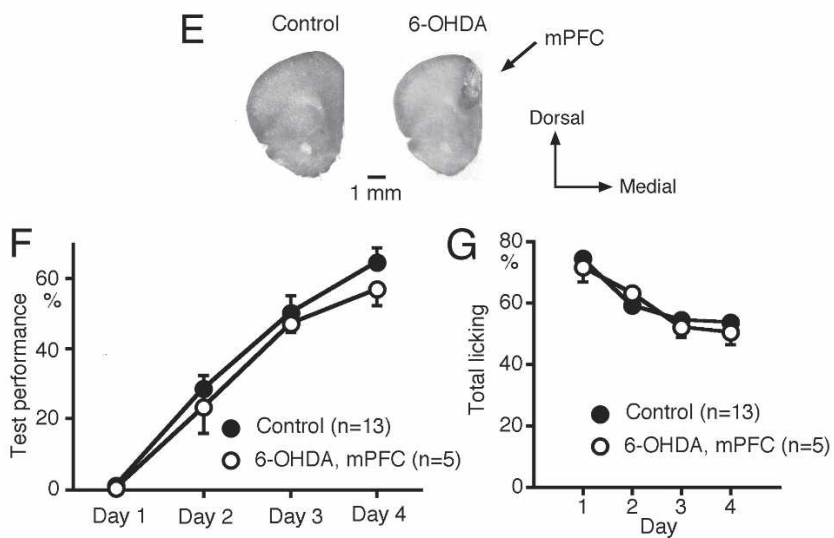

Figure 4. Effects of 6-OHDA lesions in the NAc on sound discrimination learning. (A) Bilateral 6-OHDA lesions in the NAc attenuated sound sequence discrimination learning $\left({ }^{*} P<0.05\right)$. $(B)$ Total number of trials with licking during the test session was not attenuated by the 6-OHDA lesions. (C) 6-OHDA lesions attenuated discrimination between the PT and AM sound sequence components $\left({ }^{*} P<0.05\right)$. (D) 6-OHDA lesions attenuated discrimination learning between AMs with modulation depths of $70 \%$ and $30 \%\left({ }^{*} P<0.05\right)$. (E) Immunostaining of tyrosine hydroxylase in the mPFC of a control rat (left) and a rat injected with 6-OHDA to the MPFC (right). $(F, G)$ 6-OHDA lesions in the MPFC had no significant effect on sound sequence discrimination learning $(F)$ or licking behavior $(G)$.

min prior to each test session. Sound sequence discrimination learning was attenuated by chlorpromazine (data not shown). However, the total number of trials with licking responses during the test sessions was also attenuated (data not shown), thus the role of dopaminergic inputs in sound sequence discrimination learning per se is uncertain. Therefore, the role of dopaminergic inputs in sound sequence discrimination learning was investigated using receptor subtype selective dopamine antagonists.

SCH23390 (0.2 mg/kg, i.p.), a D1 receptor antagonist, applied 30 min prior to each test session suppressed licking behavior $(P<0.05)$ (Fig. 6A). SCH23390 at a higher dose $(1.0 \mathrm{mg} / \mathrm{kg}$, $n=2)$ suppressed licking severely in the first session, so that we canceled test sessions of days 2-4. SCH23390 at the dose of 0.05 $\mathrm{mg} / \mathrm{kg}$ had effect neither on licking nor test performance of sound sequence discrimination $(n=3)$ (data not shown). These findings indicate that the effect of SCH23390 on licking behavior is dose dependent. Suppression of licking by SCH23390 was prominent in the first session (Fig. 6A), suggesting that SCH23390 suppressed licking behavior in unfamiliar conditions but not in familiar conditions. Therefore, rats were overtrained to lick the spout in response to sound stimulation for $2 \mathrm{~d}$ before the sound sequence discrimination test. After this overtraining, SCH23390 had no significant effect on licking behavior (Fig. 6B). Sound sequence discrimination learning was not significantly affected by SCH23390 in the overtrained rats (Fig. 6C). These findings strongly suggest that activation of D1 receptors is required for eliciting licking behavior in unfamiliar conditions but not for sound sequence discrimination learning per se.

\section{Attenuation of sound sequence discrimination learning by D2 family receptor antagonists}

We investigated the role of D2 family receptors in sound sequence discrimination learning. Haloperidol $(0.5$ and $2.0 \mathrm{mg} / \mathrm{kg}$, i.p.), a D2 family receptor antagonist, attenuated sound sequence discrimination learning $(P<0.05)$ (Fig. 7A). The total number of trials with licking responses during the test sessions was not attenuated by $0.5 \mathrm{mg} / \mathrm{kg}$ haloperidol (Fig. 7B), while haloperidol at a higher dose $(2.0 \mathrm{mg} / \mathrm{kg})$ suppressed licking behavior $(P<0.05)$ (Fig. 7B). Haloperidol $(0.5 \mathrm{mg} / \mathrm{kg})$ had no effect on discrimination between the two components of the sound sequences (Fig. 7C). In the rats overtrained for licking responses, haloperidol (0.5 $\mathrm{mg} / \mathrm{kg}$ ) also attenuated sound sequence discrimination learning $(P<0.01)$ (Fig. 7D), but had no effect on licking response (Fig. 7E). Taken together, it is strongly suggested that activation of D2 family receptors is required for sound sequence discrimination learning.

We further tested the effects of D2 family receptor antagonists. Raclopride (1 mg/kg, i.p.), a D2-selective antagonist, or clozapine (5 mg/kg, i.p.), a D4-selective antagonist, had slight, but not significant, effects on sound sequence discrimination learning (Fig. 8A,B). However, application of raclopride plus clozapine attenuated sound sequence discrimination learning significantly $(P<0.05)$ (Fig. 8B). Raclopride, clozapine, or simultaneous application of both reagents, had no significant effect on licking behavior (Fig. 8C,D,E). These findings suggest that both D2 and D4 receptors are required for sound sequence discrimination learning.

\section{Effects of dopaminergic antagonists on acquired sound sequence discrimination}

Activation of cholinergic receptors is required for the acquisition of sound sequence discrimination, but not for acquired sound sequence discrimination (Kudoh et al. 2004). We tested whether

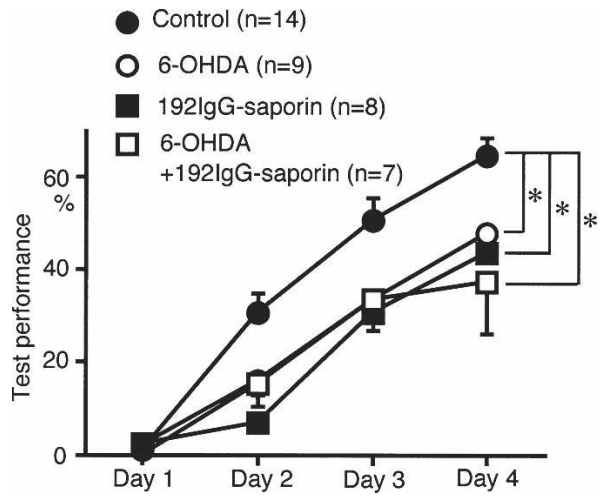

Figure 5. Effects of concurrent application of 6-OHDA plus 192lgGsaporin to the $A C$ on sound sequence discrimination learning. A mixture of $192 \mathrm{lgG}$-saporin plus 6-OHDA was injected into the AC $1 \mathrm{wk}$ prior to the test sessions. Attenuation of test performance produced by $192 \mathrm{lgG}$ saporin plus 6-OHDA was similar to that induced by 6-OHDA or 192lgGsaporin alone $\left({ }^{*} P<0.05\right)$. Data for 192lgG-saporin alone are reproduced from our previous paper (Kudoh et al. 2004). 

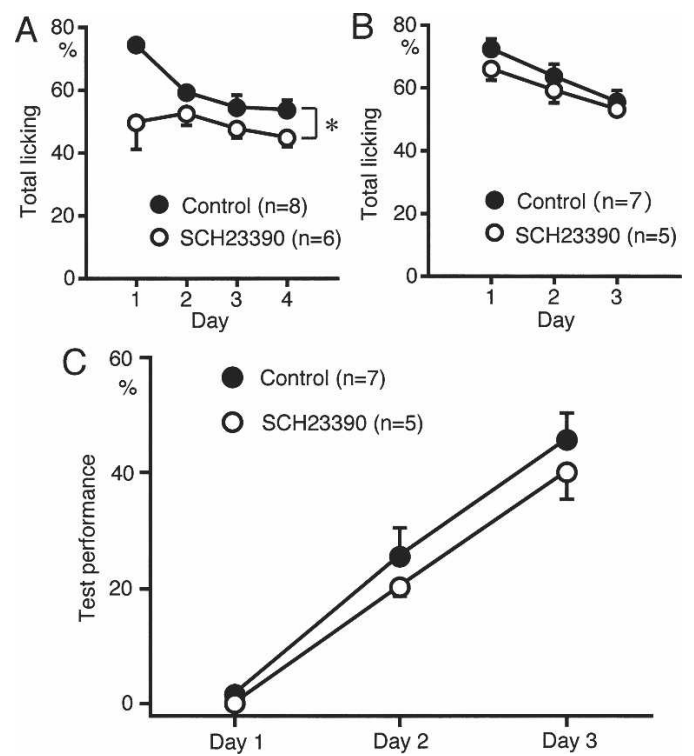

Figure 6. Effects of D1 receptor antagonist on licking behavior. $(A)$ $\mathrm{SCH} 23390(0.2 \mathrm{mg} / \mathrm{kg}$, i.p.) reduced the total number of trials with licking behavior $\left({ }^{*} P<0.05\right) .(B, C)$ Rats were overtrained to lick the spout in response to sound presentation for $2 \mathrm{~d}$ before the sound sequence discrimination test. In the overtrained rats, $\mathrm{SCH} 23390$ had no significant effect on licking behavior $(B)$ or on sound sequence discrimination (C).

dopamine receptor antagonists had any effect on acquired sound sequence discrimination performance. SCH23390 $(0.5 \mathrm{mg} / \mathrm{kg})$ or haloperidol $(0.5 \mathrm{mg} / \mathrm{kg})$ was administered prior to the fifth test session, which was conducted $1 \mathrm{wk}$ after the usual four learning test sessions. Neither drug had any effect on the performance in the fifth session (Fig. 9A,B). Licking behavior was not affected by either drug (data not shown). These findings demonstrate that activation of dopamine receptors is not required for acquired sound sequence discrimination.

\section{Discussion}

\section{Roles of the $\mathrm{AC}$ in sound sequence discrimination learning}

It has been reported that the $\mathrm{AC}$ has an important role in sound sequence discrimination. The auditory response of AC neurons can be modulated by stimulus sequence (McKenna et al. 1989; Brosch et al. 1999; Brosch and Schreiner 2000), and some AC neurons respond selectively to a particular sequential combination of sounds (Suga et al. 1978; Kilgard and Merzenich 2002; Nakahara et al. 2004). These studies suggest that sound sequences can be coded by AC neurons. Ablation of the AC impairs discrimination of temporal sound patterns (Diamond and Neff 1957; Kaas et al. 1967; Dewson and Cowey 1969). In the present study, the electrolytic lesions of the AC impaired sound sequence discrimination learning (Fig. 2B,C). Meanwhile, some type of sound discrimination, such as frequency or intensity discrimination, is not disturbed by AC lesions (Ono et al. 2006). In the present study, lesions of the AC had no significant effect on discrimination between components of sound sequences (Fig. $2 \mathrm{D})$. It is suggested that the AC plays an important role in discrimination learning of sound sequences, while discrimination between components of sound sequences depends on the auditory thalamus.

In our previous study, sound sequence discrimination was negatively correlated with the interval between the two sound sequence components (Kudoh et al. 2004), indicating that dis- crimination is achieved not only by recognition of each sound component, but also by the relationship between the two. When sound sequence discrimination learning has been established, however, subsequent discrimination between the sound components is affected by prior learning, as if the learned rats recognize only the first component of the sequential stimuli (Kudoh et al. 2004). Therefore, an essential step required for sound sequence discrimination learning may be formation of selective attention to the first component of sequential stimuli. Such selective attention may be formed by cholinergic inputs to the AC that are required for sound sequence discrimination learning (Kudoh et al. 2004). Dopaminergic inputs to the AC might also be important for the formation of selective attention, since reward signals are thought to be mediated by dopaminergic inputs (Bao et al. 2001; Schultz 2001).

\section{Dopaminergic inputs to the $A C$ required for sound sequence discrimination learning}

It has been suggested that mesocortical dopaminergic inputs play a role in the mPFC and the sensory cortex (Bradshaw et al. 1985; Gottberg et al. 1988; Parkinson 1989; Reyes et al. 2002). Dopaminergic fibers have been found in the AC (Campbell et al. 1987; Harper and Wallace 1995; Goldsmith and Joyce 1996). Neuronal plasticity in the AC is evoked by paired auditory and electrical stimulation of the ventral tegmental area (Bao et al. 2001, 2003).

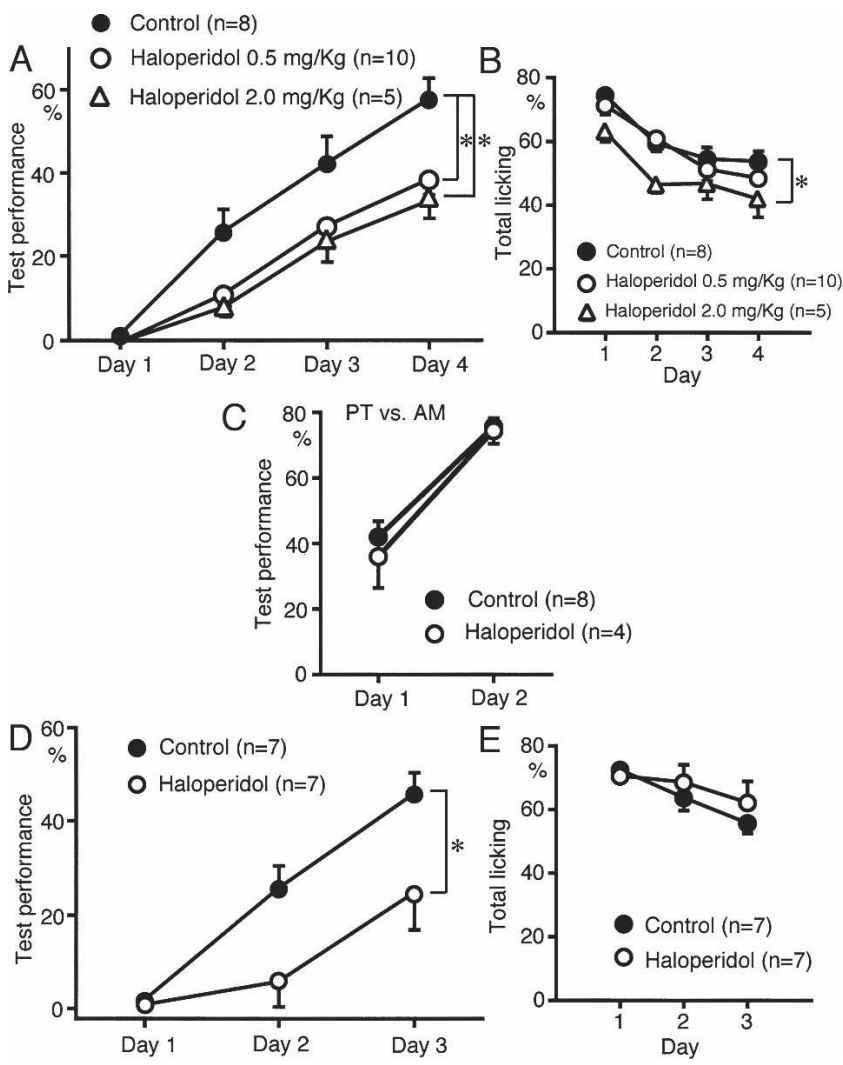

Figure 7. Effects of D2 family antagonist on sound sequence discrimination learning. (A) Haloperidol $(0.5$ and $2.0 \mathrm{mg} / \mathrm{kg}$, i.p.) attenuated sound sequence discrimination $\left({ }^{*} P<0.05\right)$. (B) Haloperidol $(0.5 \mathrm{mg} / \mathrm{kg})$ had no significant effect on licking behavior, while haloperidol at a higher dose $(2.0 \mathrm{mg} / \mathrm{kg})$ suppressed licking $\left({ }^{\star} P<0.05\right)$. (C) Haloperidol had no significant effect on discrimination between the sound sequence components. $(D, E)$ Rats were overtrained to lick the spout in response to sound presentation for $2 \mathrm{~d}$ before the sound sequence discrimination test. Haloperidol attenuated sound sequence discrimination $\left(D,{ }^{*} P<0.01\right)$, while it had no effect on total licking $(E)$.

\section{Learning \& Memory}



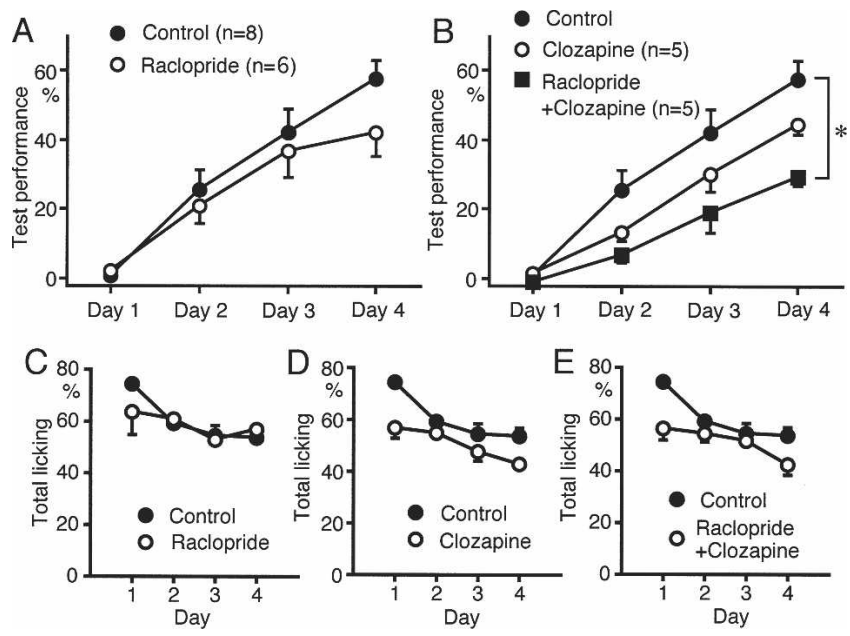

Figure 8. Effects of D2- and D4-specific antagonists on sound sequence discrimination learning. (A) D2 antagonist raclopride $(1 \mathrm{mg} / \mathrm{kg}$, i.p.) had a slight but nonsignificant effect on sound sequence discrimination learning. (B) D4 antagonist clozapine (5 mg/kg, i.p.) had a slight but nonsignificant effect. Simultaneous application of raclopride plus clozapine significantly attenuated sound sequence discrimination $\left({ }^{*} P<0.05\right)$. $(C, D, E)$ Licking behavior was not significantly suppressed by raclopride alone $(C)$, clozapine alone $(D)$, or simultaneous application of both agents $(E)$.

In the animals undergoing auditory discrimination learning, increases in dopamine and homovanillic acid, a dopamine metabolite, are detected in the AC (Scheich et al. 1997; Stark and Scheich 1997). In the present study, 6-OHDA lesions in the AC attenuated sound sequence discrimination learning (Fig. 3B), but not discrimination between the two sound sequence components or between AMs (Fig. 3D,E). 6-OHDA ( $8 \mu \mathrm{g})$ was injected to the AC under the application of desipramine, a blocker of noradrenalin uptake, which is a similar condition to previous studies (Kelly and Iversen 1976; Bubser and Koch 1994). Reduction in optical density of tyrosine hydroxylase could be found in the present study, although the immunohistochemical staining does not represent the tyrosine hydroxylase level quantitatively. It is reported that 6-OHDA injection leads to marked depletion (87\%) of dopamine in the neocortex (Bubser and Koch 1994), although it may decrease noradrenalin and serotonin even in the presence of desipramine (Bubser and Koch 1994). These findings strongly suggest that dopaminergic inputs to the AC have an important role in sound sequence discrimination learning.

\section{Possible mechanisms of sound sequence discrimination} learning and the role of dopaminergic inputs to the $A C$ In the present study, the attenuation of sound sequence discrimination learning produced by 6-OHDA or 192IgG-saporin alone, or 6-OHDA plus 192IgG-saporin, applied to the AC was similar to that of electrolytic lesions in the AC (Figs. 2C, 3B, and 5), indicating that both dopaminergic and cholinergic inputs have a critical role in the sound discrimination learning function of the AC. In our previous study, synaptic potentiation induced by heterosynaptic sequential stimulation was investigated in slices obtained from the rat AC (Seki et al. 2001). When tetanic stimulation was applied sequentially to two different sites in the white matter, synaptic potentiation in the supragranular pyramidal neurons was induced by the earlier but not the later stimulation. In sound sequence discrimination learning, rats use the earlier sound components as a critical cue for discrimination (Kudoh et al. 2004). The sequence dependence of synaptic potentiation is abolished by muscarinic antagonists (Seki et al. 2001), as the sound sequence discrimination learning is attenuated by application of 192IgG-saporin to the AC (Kudoh et al. 2004). These similarities between the sequence-dependent plasticity in the AC slices and sound sequence discrimination learning suggest that the former is the cellular mechanism for the latter. Dopamine facilitates the induction of LTP and LTD in the neocortex (LawTho et al. 1995; Otani et al. 1998; Blond et al. 2002). Therefore, it would be expected that dopaminergic inputs mediating reward signals would facilitate the induction of sequence-dependent synaptic potentiation in the AC during the trials with $\mathrm{S}^{+}$presentation, while no facilitation would take place during the trials with $\mathrm{S}^{-}$. This differential facilitation of sequence-dependent synaptic potentiation in the AC by dopaminergic inputs may explain the mechanisms underlying the facilitatory role of dopaminergic inputs in sound sequence discrimination learning. The resultant enhancement of neuronal activity in the AC to the first sound of sequences might play an important role in sound sequence memory.

\section{Dopaminergic inputs to the NAc facilitating the association between $\mathrm{S}^{+}$and reward}

In the present study, 6-OHDA lesions in the NAc (Fig. 4A) but not the mPFC (Fig. 4F) attenuated sound sequence discrimination learning. The NAc is one of the targets of the mesolimbic dopaminergic fibers (Fallon and Moore 1978). D1 and D2 dopamine receptors are present in the NAc (Weiner et al. 1991; Mengod et al. 1992). The NAc receives glutamatergic inputs from the prefrontal cortex and the limbic system such as the amygdala and hippocampus, and projects into the ventral pallidum with GABAergic outputs (Amalric and Koob 1993; Schultz 2001). These circuits, including the NAc, play an important part in reward, motivation, or goal-directed behavior (Schultz 2001; Salamone et al. 2005). Neurons in the NAc respond to sensory stimuli that are combined with rewards or predicted rewards (Schultz 2001). Dopamine release can be detected in the NAc during Pavlovian or instrumental conditioning (Phillips et al. 2003), and enhances the contrast between stronger and weaker excitations in the NAc

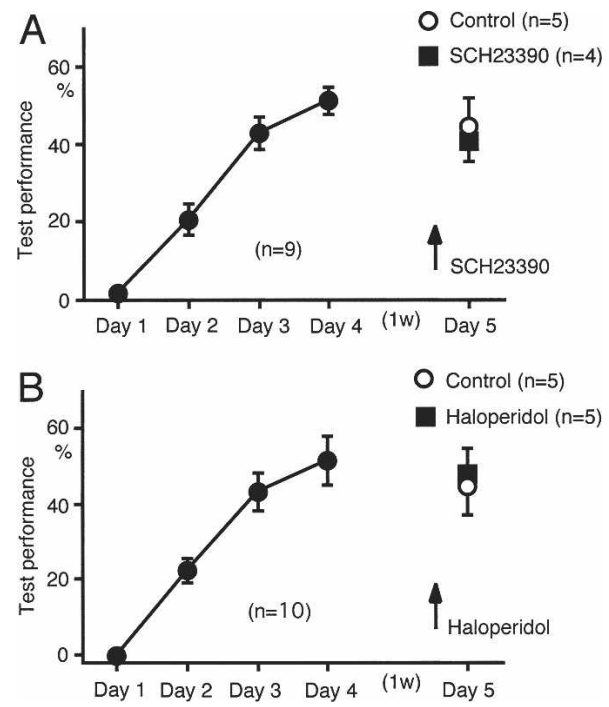

Figure 9. Effects of dopaminergic antagonists on the acquired performance of sound sequence discrimination. (A) SCH23390 $(0.5 \mathrm{mg} / \mathrm{kg}$, i.p.) had no significant effect on the acquired test performance achieved during four consecutive test sessions conducted 1 wk previously. (B) Haloperidol ( $0.5 \mathrm{mg} / \mathrm{kg}$, i.p.) had no effect on the acquired test performance. 
(Nicola et al. 2004). Furthermore, dopamine facilitates induction of LTP and LTD in the NAc or striatum (Kombian and Malenka 1994; Thomas and Malenka 2003; Wickens et al. 2003), It is reported that the dopaminergic inputs to the NAc are required for discrimination learning of visual stimuli (Parkinson et al. 2002). In the present study, sound sequence discrimination (Fig. 4A) and discrimination between the sound sequence components or between AMs (Fig. 4C,D) were attenuated by 6-OHDA lesions in the NAc. The lesions did not affect licking behavior during the test sessions (Fig. 4B) or during the procedural training prior to the test sessions. Taken together, these findings suggest that the dopaminergic inputs to the NAc facilitate the association between $\mathrm{S}^{+}$and reward.

\section{Differential roles of D1 and D2 family receptors in sound sequence discrimination learning}

Differential functions of D1 and D2 receptors have been suggested in feeding, drinking, or discrimination learning (Clifton et al. 1991; Courtiere et al. 2003; Yue et al. 2004). D1 antagonists induce catalepsy (Barnett et al. 1988; Ossowska et al. 1990) and attenuate feeding, drinking, and locomotor activity (Clifton et al. 1991; Chinen and Frussa-Filho 1999; Verty et al. 2004). In the present study, SCH23390, a D1 antagonist, suppressed licking behavior, and the suppressive effect was marked in the first test session on day 1 (Fig. 6A). In overtrained rats, neither licking behavior nor sound sequence discrimination learning was affected by SCH23390 (Fig. 6B,C). Altogether, it is considered that D1 receptors are not responsible for sound sequence discrimination learning, while they are required for eliciting licking behavior in unfamiliar conditions.

Haloperidol, a D2 family antagonist, impaired sound sequence discrimination learning (Fig. 7A,D), while it had no significant effect on discrimination between components of sound sequences (Fig. 7C). Antagonists of D2 family receptors can induce catalepsy (Ellenbroek et al. 1985; Ossowska et al. 1990). Haloperidol at the high dose $(2.0 \mathrm{mg} / \mathrm{kg})$ suppressed licking behavior in the present study (Fig. 7B). However, $0.5 \mathrm{mg} / \mathrm{kg}$ haloperidol, which had no effect on licking (Fig. 7B,E), attenuated test performance of sound sequence discrimination (Fig. 7A,D), indicating that sound sequence discrimination learning per se depends on D2 family receptors. Haloperidol had no effect on acquired sound sequence discrimination (Fig. 9B), demonstrating that D2 family receptors are required for acquisition but not maintenance of sound sequence discrimination learning.

Application of D2 and D4 receptor antagonists significantly attenuated sound sequence discrimination (Fig. 8B), confirming dependence of sound sequence discrimination learning on D2 family receptors. Since concurrent administration of D2 and D4 antagonists was required for impairment of sound sequence discrimination learning, dopamine receptors in multiple brain sites may be involved in the learning. Sound sequence discrimination may require working memory, which is dependent on dopamine receptors in the mPFC (Glickstein et al. 2002). However, 6-OHDA injection to the $\mathrm{MPFC}$ had no effect on sound sequence discrimination learning (Fig. 4F), suggesting that the effect of D2 family antagonists on sound sequence discrimination learning is not attributable to impairment of working memory in the mPFC. It is known that D2 family receptors are present in the AC (Campbell et al. 1987; van der Weide et al. 1987; Goldsmith and Joyce 1996). 6-OHDA lesion of the AC attenuated sound sequence discrimination learning but not discrimination of sound sequence components (Fig. 3B,D), which is comparable to the effects of haloperidol (Fig. 7A,C,D). These results imply that acquisition of sound sequence discrimination is facilitated by activation of D2 family receptors in the AC.

\section{Materials and Methods}

The experiments in the present study were performed in accordance with the guidelines for animal experimentation in Niigata University, Japan and approved by the ethics committee of Niigata University.

\section{Behavioral tests}

The procedure for the sound discrimination test was modified from those described in our previous studies (Watanabe et al. 2001; Ono et al. 2003; Kudoh et al. 2004). Male Wistar rats (6-8 wk old) were maintained at $22^{\circ}-24^{\circ} \mathrm{C}$ and $\sim 60 \%$ humidity, and provided with light in a daytime cycle from 06.00 to $18.00 \mathrm{~h}$. Rats were deprived of water for $24 \mathrm{~h}$, while being freely provided with dry food pellets. After water deprivation, rats were placed in a Skinner box equipped with a waterspout and speaker (Fig. 1A). This box was placed in a soundproof room. In procedural training prior to the discrimination test (Fig. 1C), the rats were trained to respond to sound stimuli by licking the spout. The same sound stimuli were also used in the following discrimination test unless otherwise specified. The training was conducted for $45 \mathrm{~min}$, during which a small amount of $0.1 \%$ saccharine solution was supplied through the spout when the rat licked the spout during presentation of sound stimuli. Licking was monitored as changes in electrical resistance between the spout of the stainless steel pipe and the surrounding silver plate. After training, all the rats learned to lick the spout in response to sound stimuli.

Six hours after the procedural training, the rats underwent the sound sequence discrimination test, in which two sound components were presented sequentially. Licking of the spout during presentation of one of the two possible sequences was rewarded with a $0.1 \%$ saccharine solution supplied at a flow rate of $3 \mu \mathrm{L} / \mathrm{sec}$, while licking in response to the other sound sequence was not rewarded. In each trial, the rewarded $\left(\mathrm{S}^{+}\right)$or unrewarded $\left(\mathrm{S}^{-}\right)$sequences were presented randomly. The trial was repeated every minute throughout a test session of $12 \mathrm{~h}$ from 20.00 to $08.00 \mathrm{~h}$ (Fig. 1C). If a rat spontaneously licked the spout immediately (50 msec) before presentation of the sound stimuli, the trial was aborted. Four test sessions were conducted over four consecutive days (Fig. 1C). Sound presentation, water supply, and recording of licking behavior were automatically controlled by a computer using software developed by the authors. The percentages of trials in which the rats licked the spout during sound presentation were calculated separately for the $\mathrm{S}^{+}$and $\mathrm{S}^{-}$ groups, and test performance was estimated as the difference. The test performance in the first $6 \mathrm{~h}$ of the session was used for analysis because the rats licked the spout less frequently during the last $6 \mathrm{~h}$

To test for discrimination of sound sequence, a PT $(6 \mathrm{kHz}$ sine wave) and an AM tone ( $9 \mathrm{kHz}$ sine wave modulated by a 100 $\mathrm{Hz}$ sawtooth wave, modulation depth: 100\%) were used as the components of the sequential stimuli (Fig. 1B). The duration of each sound component was $200 \mathrm{msec}$ with a rise/fall time of 10 msec, and the interval between the two components was 50 msec. In each trial, one of the two possible sequences was repeated at $0.5 \mathrm{~Hz}$ for $10 \mathrm{sec}$. The sound intensity in the Skinner box was $\sim 75 \mathrm{~dB}$ SPL. Licking the spout within the $10 \mathrm{sec}$ of $\mathrm{S}^{+}$trial was rewarded with saccharine solution during the $10 \mathrm{sec}$. In another group of rats, discrimination between the two sound sequence components was tested by presenting either the PT or AM only at 1 or $2 \mathrm{~Hz}$ for $10 \mathrm{sec}$ during each trial. This test session was conducted over two consecutive days. Discrimination of AMs with different modulation depths (70\% vs. 30\%) was also tested during four test sessions in the other group of rats.

In some experiments, rats were overtrained to lick the spout in response to a sound stimulus before the sound sequence discrimination test. In this procedural overtraining, an AM sound (carrier frequency $7350 \mathrm{~Hz}$, modulation frequency $100 \mathrm{~Hz}$, modulation depth 33\%) was repeated at $1 \mathrm{~Hz}$ for $10 \mathrm{sec}$, during which licking the spout was rewarded with a $0.1 \%$ saccharine solution. This trial was repeated at 2-min intervals for $12 \mathrm{~h}$ on two consecutive days prior to the discrimination test. 


\section{Electrolytic lesions in the AC}

Electrolytic lesions were produced bilaterally in the AC $1 \mathrm{wk}$ prior to the beginning of the discrimination test in 19 rats. The rats were anesthetized with isoflurane $\left(1.5 \%\right.$ in $\mathrm{O}_{2}$ gas), and the surgical operation was conducted under sterilized conditions. After a subcutaneous injection of bupivacaine, a local anesthetic, the skin covering the skull was incised. Craniotomy was conducted over the AC. A steel electrode $(0.3 \mathrm{~mm}$ diameter) insulated with vinyl chloride except for the $0.5-\mathrm{mm}$ tip was penetrated perpendicular to the AC to a depth of $0.8 \mathrm{~mm}$ at six locations for each hemisphere (anteroposterior, $-2.6,-4.1$, and -5.6 ; dorsoventral, -3.5 and $-5.0 \mathrm{~mm}$ to Bregma) (Paxinos and Watson 1986). Electrolytic lesions were produced by passing a constant current of $4 \mathrm{~mA}$ for $10 \mathrm{sec}$. The craniotomy without the AC lesions was conducted as a sham operation in five rats. The incised skin was sutured after local application of fradiomycin. After test cessation, histological examinations were conducted for rats with $\mathrm{AC}$ lesions. The rats were deeply anesthetized with pentobarbital $(100 \mathrm{mg} / \mathrm{kg}$, i.p.), and transcardially perfused with phosphatebuffered saline (PBS) followed by $4 \%$ paraformaldehyde in PBS. The brain was removed and further fixed in paraformaldehyde PBS. Tissue sections of $30 \mu \mathrm{m}$ were cut using a cryotome (AS620; Shandon) and stained with cresyl violet.

\section{Application of 6-OHDA or 192 IgG-saporin to the AC}

6-OHDA, a dopamine neurotoxin (Kelly and Iversen 1976), was injected bilaterally to the AC, mPFC, or NAc 1 wk prior to the discrimination test. 6-OHDA was dissolved in PBS containing $0.01 \%$ L-ascorbic acid, as an antioxidant. Desipramine, a blocker of noradrenalin transport, dissolved in saline was administered ( $25 \mathrm{mg} / \mathrm{mL}$ per $\mathrm{kg}$, i.p.) $30 \mathrm{~min}$ prior to 6-OHDA application. A guide cannula $(0.6 \mathrm{~mm}$ diameter) was inserted stereotaxically through a small opening in the skull. 6-OHDA was injected bilaterally to the AC (anteroposterior, -5.3 ; mediolateral \pm 4.0 ; dorsoventral $-4.0 \mathrm{~mm}$ to Bregma) in 18 rats, and to the NAc (anteroposterior, +1.7 ; mediolateral \pm 1.5 ; dorsoventral -6.7 $\mathrm{mm}$ to Bregma) in 15 rats. In five rats, 6-OHDA was injected to the $\mathrm{mPFC}$ at four locations for each hemisphere (anteroposterior, +2.5 and +3.5 ; mediolateral \pm 0.5 ; dorsoventral $-2,5$ and -3.5 $\mathrm{mm}$ to Bregma). 6-OHDA ( $8 \mu \mathrm{g}$ in $1 \mu \mathrm{L}$ of PBS at each location) was injected through a stainless steel tube $(0.3 \mathrm{~mm}$ diameter $)$ using a syringe pump (CFV3200; Nihon Kohden) over a 10-min period. To allow diffusion of the drug into the brain, the tube was kept in the same position for a further $5 \mathrm{~min}$. In our previous study, the effect of 192IgG-saporin, an immunotoxin specific to cholinergic neurons, was investigated (Kudoh et al. 2004). This compound consists of a 192IgG antibody to low-affinity neurotrophin receptors conjugated with saporin, a ribosomeinactivating protein (Wiley et al. 1991). In seven rats, 192IgGsaporin (64 ng) and 6-OHDA ( $8 \mu \mathrm{g}$ in $1 \mu \mathrm{L}$ of PBS) were simultaneously applied to the bilateral AC. Sham-lesioned rats had the same volume of vehicle injected, using identical procedures.

To verify the dopaminergic denervation following 6-OHDA injection, brain tyrosine hydroxylase, the rate-limiting enzyme in the synthesis of catecholamines, was immunostained after the behavioral experiments in the rats injected with 6-OHDA. Brain sections were immersed in PBS containing 1.5\% normal goat serum (blocking solution) for $30 \mathrm{~min}$ at room temperature, and then reacted with a 1:500 dilution of a rabbit antibody for tyrosine hydroxylase (Chemicon) in PBS for $24 \mathrm{~h}$ at $4^{\circ} \mathrm{C}$. Immunohistochemical detection was conducted using the avidin-biotinperoxidase technique with the Vectastain $\mathrm{ABC}$ kit and $\mathrm{DAB}$ substrate kit (Vector Laboratories).

\section{Systemic drug application}

Chlorpromazine, SCH23390, or raclopride was dissolved in saline. Clozapine was diluted in 3\% acetic acid solution ( $\mathrm{pH} \mathrm{5-6).}$ These solutions with appropriate drug concentrations $(1 \mathrm{~mL} / \mathrm{kg})$ were applied intraperitoneally $30 \mathrm{~min}$ prior to the beginning of each test session. Haloperidol was dissolved in ethanol and diluted 20 times in saline, and the suspension was applied intraperitoneally $30 \mathrm{~min}$ prior to the test session. As a control for drug application, saline $(1 \mathrm{~mL} / \mathrm{kg})$ was administered. Chlorpromazine, SCH-23390, raclopride, clozapine, 6-OHDA, desipramine, and Lascorbic acid were purchased from Sigma. 192IgG-saporin was purchased from Vector Laboratories and haloperidol from Wako.

\section{Acknowledgments}

We thank Y. Tamura and N. Taga for technical assistance. This work was supported by grants from the Japanese Government.

\section{References}

Amalric, M. and Koob, G.F. 1993. Functionally selective neurochemical afferents and efferents of the mesocorticolimbic and nigrostriatal dopamine system. Prog. Brain Res. 99: 209-226.

Bao, S., Chan, V.T., and Merzenich, M.M. 2001. Cortical remodelling induced by activity of ventral tegmental dopamine neurons. Nature 412: 79-83.

Bao, S., Chan, V.T., Zhang, L.I., and Merzenich, M.M. 2003. Suppression of cortical representation through backward conditioning. Proc. Natl. Acad. Sci. 100: 1405-1408.

Barnett, A., Iorio, L.C., McQuade, R., and Chipkin, R.E. 1988. Pharmacological and behavioral effects of D1 dopamine antagonists. Adv. Exp. Med. Biol. 235: 137-144.

Blond, O., Crepel, F., and Otani, S. 2002. Long-term potentiation in rat prefrontal slices facilitated by phased application of dopamine. Eur. J. Pharmacol. 438: 115-116.

Bradshaw, C.M., Sheridan, R.D., and Szabadi, E. 1985. Excitatory neuronal responses to dopamine in the cerebral cortex: Involvement of D2 but not D1 dopamine receptors. Br. J. Pharmacol. 86: 483-490.

Brosch, M. and Schreiner, C.E. 2000. Sequence sensitivity of neurons in cat primary auditory cortex. Cereb. Cortex 10: 1155-1167.

Brosch, M., Schulz, A., and Scheich, H. 1999. Processing of sound sequences in macaque auditory cortex: Response enhancement. J. Neurophysiol. 82: 1542-1559.

Bubser, M. and Koch, M. 1994. Prepulse inhibition of the acoustic startle response of rats is reduced by 6-hydroxydopamine lesions of the medial prefrontal cortex. Psychopharmacology 113: 487-492.

Campbell, M.J., Lewis, D.A., Foote, S.L., and Morrison, J.H. 1987. Distribution of choline acetyltransferase-, serotonin-, dopamine- $\beta$-hydroxylase-, tyrosine hydroxylase-immunoreactive fibers in monkey primary auditory cortex. J. Comp. Neurol. 261: 209-220.

Chinen, C.C. and Frussa-Filho, R. 1999. Conditioning to injection procedures and repeated testing increase SCH 23390-induced catalepsy in mice. Neuropsychopharmacology 21: 670-678.

Civelli, O., Bunzow, J.R., and Grandy, D.K. 1993. Molecular diversity of the dopamine receptors. Annu. Rev. Pharmacol. Toxicol. 33: 281307.

Clifton, P.G., Rusk, I.N., and Cooper, S.J. 1991. Effects of dopamine D1 and dopamine D2 antagonists on the free feeding and drinking patterns of rats. Behav. Neurosci. 105: 272-281.

Courtiere, A., Hardouin, J., Goujon, A., Vidal, F., and Hasbroucq, T. 2003. Selective effects of low-dose dopamine D1 and D2 receptor antagonists on rat information processing. Behav. Pharmacol. 14: $589-598$.

Dewson, J.H. and Cowey, A. 1969. Discrimination of auditory sequences by monkeys. Nature 222: 695-697.

Diamond, I.T. and Neff, W.D. 1957. Ablation of temporal cortex and discrimination of auditory patterns. J. Neurophysiol. 20: 300-315.

Ellenbroek, B., Schwarz, M., Sontag, K.H., Jaspers, R., and Cools, A. 1985. Muscular rigidity and delineation of a dopamine-specific neostriatal subregion: Tonic EMG activity in rats. Brain Res. 345: $132-140$.

Fallon, J.H. and Moore, R.Y. 1978. Catecholamine innervation of the basal forebrain. IV. Topography of the dopamine projection to the basal forebrain and neostriatum. J. Comp. Neurol. 180: 545-580.

Gaese, B.H. and Ostwald, J. 1995. Temporal coding of amplitude and frequency modulation in the rat auditory cortex. Eur. J. Neurosci. 7: 438-450.

Glickstein, S.B., Hof, P.R., and Schmauss, C. 2002. Mice lacking dopamine D2 and D3 receptors have spatial working memory deficits. J. Neurosci. 22: 5619-5629.

Goldsmith, S.K. and Joyce, J.N. 1996. Dopamine D2 receptors are organized in bands in normal human temporal cortex. Neuroscience 74: $435-451$.

Gottberg, E., Montreuil, B., and Reader, T.A. 1988. Acute effects of lithium on dopaminergic responses: Iontophoretic studies in the rat visual cortex. Synapse 2: 442-449.

Gurden, H., Takita, M., and Jay, T.M. 2000. Essential role of D1 but not D2 receptors in the NMDA receptor-dependent long-term 
potentiation at hippocampal-prefrontal cortex synapses in vivo. J. Neurosci. 20: RC106.

Harper, M.S. and Wallace, M.N. 1995. Changes in density of brainstem afferents in ferret primary auditory cortex (AI) during postnatal development. J. Anat. 186: 373-382.

Kaas, J., Axelrod, S., and Diamond, I.T. 1967. An ablation study of the auditory cortex in the cat using binaural tonal patterns. J. Neurophysiol. 30: 710-724.

Kebabian, J.W. and Calne, D.B. 1979. Multiple receptors for dopamine. Nature 277: 93-96.

Kelly, P.H. and Iversen, S.D. 1976. Selective 6OHDA-induced destruction of mesolimbic dopamine neurons: Abolition of psychostimulant-induced locomotor activity in rats. Eur. J. Pharmacol. 40: 45-56.

Kerr, J.N. and Wickens, J.R. 2001. Dopamine D-1/D-5 receptor activation is required for long-term potentiation in the rat neostriatum in vitro. J. Neurophysiol. 85: 117-124.

Kilgard, M.P. and Merzenich, M.M. 2002. Order-sensitive plasticity in adult primary auditory cortex. Proc. Natl. Acad. Sci. 99: 3205-3209.

Kombian, S.B. and Malenka, R.C. 1994. Simultaneous LTP of non-NMDA- and LTD of NMDA-receptor-mediated responses in the nucleus accumbens. Nature 368: 242-246.

Krieg, W. 1946. Connections of the cerebral cortex. I. The albino rat. A. Topography of the cortical areas. J. Comp. Neurol. 84: 221-275.

Kudoh, M., Seki, K., and Shibuki, K. 2004. Sound sequence discrimination learning is dependent on cholinergic inputs to the rat auditory cortex. Neurosci. Res. 50: 113-123.

Lachowicz, J.E. and Sibley, D.R. 1997. Molecular characteristics of mammalian dopamine receptors. Pharmacol. Toxicol. 81: 105-113.

Law-Tho, D., Desce, J.M., and Crepel, F. 1995. Dopamine favours the emergence of long-term depression versus long-term potentiation in slices of rat prefrontal cortex. Neurosci. Lett. 188: 125-128.

McKenna, T.M., Weinberger, N.M., and Diamond, D.M. 1989. Responses of single auditory cortical neurons to tone sequences. Brain Res. 481: $142-153$

Mengod, G., Villaro, M.T., Landwehrmeyer, G.B., Martinez-Mir, M.I., Niznik, H.B., Sunahara, R.K., Seeman, P., O'Dowd, B.F., Probst, A., and Palacios, J.M. 1992. Visualization of dopamine D1, D2 and D3 receptor mRNAs in human and rat brain. Neurochem. Int. 20: 33S43S.

Nakahara, H., Zhang, L.I., and Merzenich, M.M. 2004. Specialization of primary auditory cortex processing by sound exposure in the "critical period." Proc. Natl. Acad. Sci. 101: 7170-7174.

Nicola, S.M., Woodward Hopf, F., and Hjelmstad, G.O. 2004. Contrast enhancement: A physiological effect of striatal dopamine? Cell Tissue Res. 318: 93-106.

Ono, K., Kudoh, M., and Shibuki, K. 2003. Relational discrimination learning between amplitude-modulated sounds in the rat. Neurosci. Lett. 342: 171-174.

Ono, K., Kudoh, M., and Shibuki, K. 2006. The auditory cortex as a sensory interface of higher cortices in the rat. Eur. J. Neurosci. 23: 1623-1632.

Ossowska, K., Karcz, M., Wardas, J., and Wolfarth, S. 1990. Striatal and nucleus accumbens D1/D2 dopamine receptors in neuroleptic catalepsy. Eur. J. Pharmacol. 182: 327-334.

Otani, S., Blond, O., Desce, J.M., and Crepel, F. 1998. Dopamine facilitates long-term depression of glutamatergic transmission in rat prefrontal cortex. Neuroscience 85: 669-676.

Parkinson, D. 1989. Evidence for a dopaminergic innervation of cat primary visual cortex. Neuroscience 30: 171-179.

Parkinson, J.A., Dalley, J.W., Cardinal, R.N., Bamford, A., Fehnert, B. Lachenal, G., Rudarakanchana, N., Halkerston, K.M., Robbins, T.W., and Everitt, B.J. 2002. Nucleus accumbens dopamine depletion impairs both acquisition and performance of appetitive Pavlovian approach behaviour: Implications for mesoaccumbens dopamine function. Behav. Brain Res. 137: 149-163.

Paxinos, G. and Watson, C. 1986. The rat brain in stereotaxic coordinates. Academic Press, North Ryde, New South Wales, Australia.
Phillips, G.D., Setzu, E., Vugler, A., and Hitchcott, P.K. 2003. Immunohistochemical assessment of mesotelencephalic dopamine activity during the acquisition and expression of Pavlovian versus instrumental behaviours. Neuroscience 117: 755-767.

Reyes, E., Rossell, S., Paredes, D., Rada, P., Tucci, S., Gonzalez, L.E., and Hernandez, L. 2002. Haloperidol abolished glutamate release evoked by photic stimulation of the visual cortex in rats. Neurosci. Lett. 327: $149-152$

Saitoh, K., Maruyama, N., and Kudoh, M. 1981. Sustained response of auditory cortex units in the cat. In Brain mechanisms of sensation (eds. Y. Katsuki et al.), pp. 31-43. Wiley, New York.

Sakai, M., Kudoh, M., and Shibuki, K. 1999. Long-lasting enhancement of sound discrimination ability after sound exposure in rats. Neurosci. Res. 33: 87-97.

Salamone, J.D., Correa, M., Mingote, S.M., and Weber, S.M. 2005. Beyond the reward hypothesis: Alternative functions of nucleus accumbens dopamine. Curr. Opin. Pharmacol. 5: 34-41.

Scheich, H., Stark, H., Zuschratter, W., Ohl, F.W., and Simonis, C.E. 1997. Some functions of primary auditory cortex in learning and memory formation. Adv. Neurol. 73: 179-193.

Schreiner, C.E. and Urbas, J.V. 1988. Representation of amplitude modulation in the auditory cortex of the cat. II. Comparison between cortical fields. Hear. Res. 32: 49-63.

Schultz, W. 2001. Reward signaling by dopamine neurons. Neuroscientist 7: 293-302.

Seki, K., Kudoh, M., and Shibuki, K. 2001. Sequence dependence of post-tetanic potentiation after sequential heterosynaptic stimulation in the rat auditory cortex. J. Physiol. 533: 503-518.

Stark, H. and Scheich, H. 1997. Dopaminergic and serotonergic neurotransmission systems are differentially involved in auditory cortex learning: A long-term microdialysis study of metabolites. J. Neurochem. 68: 691-697.

Stark, H., Bischof, A., Wagner, T., and Scheich, H. 2000. Stages of avoidance strategy formation in gerbils are correlated with dopaminergic transmission activity. Eur. J. Pharmacol. 405: 263-275.

Suga, N., O'Neill, W.E., and Manabe, T. 1978. Cortical neurons sensitive to combinations of information-bearing elements of biosonar signals in the mustache bat. Science 200: 778-781.

Thomas, M.J. and Malenka, R.C. 2003. Synaptic plasticity in the mesolimbic dopamine system. Philos. Trans. R. Soc. Lond. B Biol. Sci. 358: $815-819$

van der Weide, J., Camps, M., Horn, A.S., and Palacios, J.M. 1987. Autoradiographic localization of dopamine D2 receptors in the rat brain using the new agonist [3H]N-0437. Neurosci. Lett. 83: 259-263.

Verty, A.N., McGregor, I.S., and Mallet, P.E. 2004. The dopamine receptor antagonist SCH 23390 attenuates feeding induced by $\Delta^{9}$-tetrahydrocannabinol. Brain Res. 1020: 188-195.

Watanabe, S., Kudoh, M., Ohnishi, K., and Shibuki, K. 2001. Long-lasting memory of sounds combined with reward in rats. Neurosci. Lett. 311: 25-28.

Weiner, D.M., Levey, A.I., Sunahara, R.K., Niznik, H.B., O'Dowd, B.F., Seeman, P., and Brann, M.R. 1991. D1 and D2 dopamine receptor mRNA in rat brain. Proc. Natl. Acad. Sci. 88: 1859-1863.

Wickens, J.R., Reynolds, J.N., and Hyland, B.I. 2003. Neural mechanisms of reward-related motor learning. Curr. Opin. Neurobiol. 13: 685-690.

Wiley, R.G., Oeltmann, T.N., and Lappi, D.A. 1991. Immunolesioning: Selective destruction of neurons using immunotoxin to rat NGF receptor. Brain Res. 562: 149-153.

Yue, E.L., Cleland, T.A., Pavlis, M., and Linster, C. 2004. Opposing effects of D1 and D2 receptor activation on odor discrimination learning. Behav. Neurosci. 118: 184-190.

Zilles, K. and Wree, A. 1985. The rat nervous system. Academic Press, Sydney.

Received April 7, 2006; accepted in revised form August 31, 2006. 


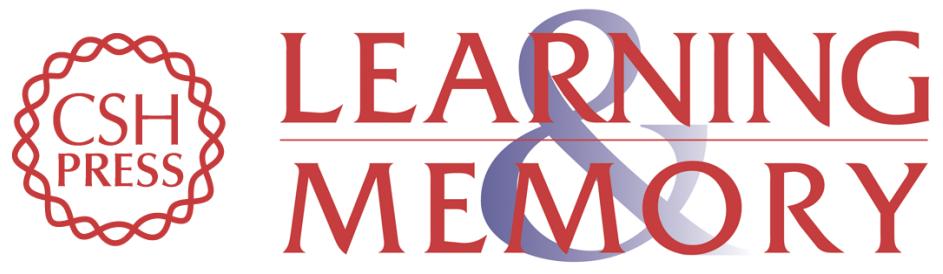

\section{Sound sequence discrimination learning motivated by reward requires dopaminergic D2 receptor activation in the rat auditory cortex}

Masaharu Kudoh and Katsuei Shibuki

Learn. Mem. 2006, 13:

Access the most recent version at doi:10.1101//m.390506

References This article cites 62 articles, 6 of which can be accessed free at: http://learnmem.cshlp.org/content/13/6/690.full.html\#ref-list-1

License

Email Alerting

Receive free email alerts when new articles cite this article - sign up in the box at the Service top right corner of the article or click here. 